\title{
PEDAGOGIA DO OPRIMIDO (1968-2018): DA REVOLUÇÃO AO REENCONTRO DA ESPERANÇA'
}

PEDAGOGY OF THE OPPRESSED (1968-2018):
FROM REVOLUTION TO THE REENCOUNTER OF HOPE
PEDAGOGÍA DEL OPRIMIDO (1968-2018):
DE LA REVOLUCÍON AL RETORNO DE LA ESPERANZA

\section{Afonso Celso Scocuglia ${ }^{1}$}

RESUMO: Este artigo incide sobre os 50 anos do livro "Pedagogia do oprimido", de Paulo Freire, concluído fora do Brasil em 1968 e publicado em 1970. Considera o livro como núcleo articulador de uma obra complexa, polifônica e em construção/reconstrução permanente. Deste prisma, como declarado por Freire, faz parte de uma trilogia que começa com a sua tese acadêmica de 1959 (Educação e atualidade brasileira), continua em "Educação como prática da Liberdade" (1965) até desaguar no livro em tela. E pode se dizer que continua em outras obras posteriores, a exemplo de "Ação cultural para a liberdade e outros escritos" (1970). Considera-se, também, o fato de que seu autor pretendeu reescrevê-la e o fez, em parte, nos livros "Pedagogia da esperança um reencontro com a Pedagogia do oprimido" (1992) e "Política e educação" (1993). Nesta reescrita, quase 25 anos depois, Freire refez conceitos, apostou em outro paradigma, descartou personagens e ênfases do livro de 1968, demonstrando o permanente movimento de reconstrução epistemológica marcado pelas circunstâncias históricas das suas práticas político-pedagógicas no Brasil, na América Latina, nos Estados Unidos, na Europa, na África.

PALAVRAS-ChaVE: Pedagogia do Oprimido. Paulo Freire. Pedagogia da Esperança.

ABSTRACT: This article focuses on the 50 years of Paulo Freire's book "Pedagogy of the Oppressed", which was completed outside Brazil in 1968 and published in 1970. It considers the book as the articulating nucleus of a complex, polyphonic and ongoing construction/reconstruction project. From this perspective, as stated by Freire, it is part of a trilogy that begins with his academic thesis of 1959 (Education and Brazilian actuality), continues in "Education the practice of Freedom" (1965) until draining into the book on screen. And it can be said that it continues in other later works, such as "Cultural action for freedom and other writings" (1970). It is also considered that his author intended to rewrite it and he did so partly in the books "Pedagogy of Hope - reliving Pedagogy of the Oppressed" (1992) and "Politics and Education" (1993). In this rewriting, almost 25 years later, Freire restated concepts, bet on another paradigm, discarded characters and emphases of the 1968 book, demonstrating the permanent movement of epistemological reconstruction marked by the historical circumstances of his political-pedagogical practices in Brazil, Latin America, the United States, Europe, and Africa.

KEYWORDS: Pedagogy of the oppressed. Paulo Freire. Pedagogy of hope.

RESUMEN: Este artículo se centra en los 50 años del libro "Pedagogía del oprimido" de Paulo Freire, que se completó fuera de Brasil en 1968 y se publicó en 1970. Considera al libro como el núcleo articulado de un proyecto complejo, polifónico y de construcción/reconstrucción en curso. Desde esta perspectiva, como lo afirma Freire, es parte de una trilogía que comienza con su tesis académica de 1959 (Educación y actualidad brasileña), continúa en "La educación como práctica de la libertad" (1965), hasta que se sumerge en el libro en pantalla. Y se puede decir que continúa en otras obras posteriores, como "Acción cultural para la libertad y otros

\footnotetext{
${ }^{1}$ Submetido em: 12/01/2019 - Aceito em:14/01/2019 - Publicado em: 17/01/2019
}

\begin{tabular}{l|l|l|l|l|l|l} 
(C) Rev. Educ. Perspec. & Viçosa, $M G$ & v.9 & n.3 & p.576-591 & set./dez. 2018 & eISSN 2178-8359 \\
\hline
\end{tabular}


escritos" (1970). También se considera que su autor tuvo la intención de reescribirlo y lo hizo, en parte, en los libros "Pedagogía de la esperanza: un reencuentro con la pedagogía del oprimido" (1992) y "Política y educación" (1993). En esta reescritura, casi 25 años después, Freire reafirmó los conceptos, apostó por otro paradigma, caracteres descartados y énfasis en el libro de 1968, que demuestra el movimiento permanente de reconstrucción epistemológica marcado por las circunstancias históricas de sus prácticas político-pedagógicas en Brasil, América Latina, Estados Unidos, Europa y Africa.

PALABRAS CLAVE: Pedagogía del oprimido. Paulo Freire. Pedagogía de la esperanza.

\section{INTRODUÇÃO}

Em 2018 o livro "Pedagogia do oprimido", de Paulo Freire, completa 50 anos. Traduzido e publicado em todo o mundo tem sucessivas edições na América Latina, América do Norte, Europa, Ásia e África. Terceira obra mais citada, segundo levantamento do Google Scholar, em trabalhos acadêmicos das ciências humanas, soma mais de 70.000 referências em trabalhos rastreados. Além disso, encontra-se entre os 100 livros mais solicitados em Universidades de língua inglesa e em um milhão de ementas de estudos universitários americanos, ingleses, australianos e neozelandeses, entre outros. No campo das Ciências da Educação é o segundo autor mais citado em todo o mundo e tem 20 das suas principais obras na relação das mais estudadas.

Certamente, as estatísticas do uso das suas obras em português e espanhol quando realizadas baterão outros recordes importantes. E embora as referências tomem a amplitude da sua trajetória intelectual como relevante totalidade, sem dúvida o livro "Pedagogia do oprimido" encontra-se no topo em termos de utilização. A UNESCO incluiu sua obra teórica e prática como "Patrimônio da Humanidade" e, também, no Programa "Memórias do Mundo". A reunião anual da AERA ${ }^{\mathrm{ii}}$ (American Educational Research Association, fundada em 1916), maior congresso de pesquisadores da educação de todo o mundo ${ }^{\mathrm{iii}}$, homenageou os 50 anos de "Pedagogia do oprimido" em abril de 2018, com 24 trabalhos apresentados durante o evento. Em suma, depois de 50 anos da escrita da sua obra mais famosa, Paulo Freire continua sendo referência mundial na área pedagógica e nas Ciências da Educação.

Pergunta necessária: e se pudéssemos quantificar as professoras e professores, instituições, escolas de todos os graus e modalidades, projetos de pesquisa e de extensão universitários, na educação de jovens e adultos, na educação nas prisões, nas Universidades e cursos de graduação e pós-graduação em todo o mundo, do Japão e da Coréia do Sul aos Estados Unidos, de países africanos de língua portuguesa aos latino-americanos, dos ibero-americanos aos saxônicos? Se pudéssemos quantificar as práticas educacionais que se utilizam e/ou se inspiram nas suas obras teríamos ainda mais clareza quanto à relevância mundial de Paulo Freire para a educação do século XX e da prospectiva para o XXI. Certamente nessas práticas

\begin{tabular}{l|l|l|l|l|l|l} 
(C) Rev. Educ. Perspec. & Viçosa, $M G$ & v.9 & n.3 & p.576-591 & set./dez. 2018 & eISSN 2178-8359 \\
\hline
\end{tabular}


se destacariam as ideias do livro "Pedagogia do oprimido" que, no Brasil, tem sua $60^{\mathrm{a}}$. edição (2016) esgotada!

Em função da sua trajetória como best-seller da Pedagogia e das Ciências da Educação, como um verdadeiro "clássico", este livro foi estudado, praticado, lido e relido, analisado, criticado e elogiado. Por isso, aqui não intencionamos analisá-la em si mesmo. Já o fizemos em "A história das ideias de Paulo Freire e a atual crise de paradigmas" (SCOCUGLIA, 1999) e em outros trabalhos e escritos ${ }^{\text {iv }}$.

Mas, o que podemos acrescer, além de comemorar sua importância seminal, 50 anos depois de escrito?

\section{PEDAGOGIA DO OPRIMIDO COMO NÚCLEO ARTICULADOR DE UMA OBRA POLIFÔNICA EM CONSTANTE MOVIMENTO}

Em primeiro lugar, é fundamental entender que este é um livro datado (1968) e "conjuntural" (embora seja, também, "estruturante" da obra de Freire). A segunda metade dos anos 1960 e, especialmente, o ano de 1968 não significaram um tempo histórico qualquer do Brasil, da América e do mundo. Poucos anos foram tão relevantes e marcantes como 1968 na história do tempo presente. Principalmente "Pedagogia do oprimido" sendo escrito na América Latina em pleno auge do embate capitalismo/socialismo, há pouco tempo do assassinato de Che Guevara na Bolívia, no Chile pré-Allende e por um exilado da ditadura militar brasileira. E, ainda, praticamente simultâneo com a Teologia da Libertação no continente. Ou seja, o contexto social, político, econômico e cultural da escrita deste livro não poderia deixar de influenciá-lo em profusão e, sem dúvida, foi determinante para sua própria existência, pelo seu próprio fundamento radical e toda a sua posterior repercussão. Podemos afirmar que não seria o mesmo se escrito em outro espaço e em outro tempo histórico. Com certeza, não seria o mesmo.

Em "Pedagogia da esperança - um reencontro com a Pedagogia do oprimido", Freire (1992, p. 45) destacou a conjuntura que lastreava a escrita do livro na segunda metade dos 1960:

A efervescência latino-americana, a presença cubana, hoje, tanto quanto antes, ameaçada pelas forças reacionárias que, cheias de si, falam da morte do socialismo, seu testemunho de que era possível mudar, as teorias guerrilheiras, a "teoria do foco", a personalidade carismática extraordinária de Camilo Torres, em que não havia dicotomia entre transcendentalidade e mundanidade, história e meta-história, a teologia da libertação, tão cedo provocando temores, tremores e raivas, a capacidade de amar de Guevara [...]. Maio de 68, os movimentos estudantis mundo afora, rebeldes, libertários; Marcuse, sua influência sobre a juventude. A China, Mao Tsé-Tung, a revolução cultural [...]. Neste sentido talvez tenha sido Santiago (do Chile), em si mesma, naquela época, o melhor centro de "ensino" e de 
conhecimento de América Latina. Aprendíamos das análises, das reações, das críticas feitas por colombianos, venezuelanos, cubanos, mexicanos, bolivianos, argentinos, paraguaios, brasileiros, chilenos, europeus.

Depois, no mesmo livro, reiterando a decisiva importância do contexto de escrita de "Pedagogia do oprimido":

\begin{abstract}
O livro apareceu numa fase histórica cheia de intensa inquietação. Os movimentos sociais na Europa, nos Estados Unidos, na América Latina, em cada espaço-tempo com suas características próprias. A luta contra a discriminação sexual, racial, cultural, de classe, a luta em defesa do ambiente, os Verdes, na Europa. Os golpes de Estado com a nova face, na América Latina, e seus governos militares que se alongaram da década anterior. Os golpes de Estado agora ideologicamente fundados, e todos eles ligados de uma ou de outra maneira ao carro-chefe do Norte, na busca de viabilizar o que lhe parecia dever ser o destino capitalista do continente. As guerrilhas na América Latina; as comunidades de base, os movimentos de libertação na África, a independência das ex-colônias portuguesas, a luta na Namíbia, Amílcar Cabral, Julius Nyerere, sua liderança na África e sua repercussão fora da África. A China. Mao. A Revolução Cultural. A extensão viva do significado de maio de 1968. As lutas político-sindicais e pedagógico-sindicais, todas obviamente políticas, sobre tudo na Itália. Guevara assassinado na década anterior e sua presença como símbolo não apenas para movimentos revolucionários latino-americanos, mas também para lideranças e ativistas progressistas de todo mundo. A guerra do Vietnã e a reação no interior dos Estados Unidos. A luta pelos direitos civis e o transbordamento do clima político-cultural dos anos 60, naquele país para década de 70 (FREIRE, 1992, p. 121).
\end{abstract}

A certeza da influência decisiva deste contexto histórico se evidencia mais e mais quando entendemos que Paulo Freire sempre foi um intelectual marcado pelos seus diversos tempos históricos: no Nordeste do Brasil dos anos 1950 e início dos 1960, na segunda metade dos anos 1960 na América latina, na Europa e na África dos anos 1970. E no retorno ao Brasil com a Anistia pós-1979, após 16 anos exilado pela ditadura. Como defendemos sempre, os "vários" Paulo Freire se fizeram na história e na construção sua própria história (SCOCUGLIA, 1999; 2015). O Paulo Freire da alfabetização de adultos no Brasil, atuando no Serviço de Extensão Cultural (SEC) da Universidade do Recife (até 1964), é outro na atuação da reforma agrária com Jacques Chanchol no Chile (segunda metade dos 1960), que é outro no Conselho Mundial das Igrejas nos anos 1970 e é outro como Secretário de Educação de São Paulo na transição dos 1980 para os 1990. E isso é notório nas suas obras escritas.

Ao mesmo tempo, ao investigarmos a obra de Freire em sua globalidade, devemos entender a "Pedagogia do oprimido" (1968) como núcleo articulador de uma elaboração teórica mais aprofundada, mais consistente e mais rigorosa, especialmente quanto à sua base de fundamentação socioeconômica e política. A aproximação aos pensamentos marxiano e marxistas $^{\mathrm{V}}$ é evidente, principalmente quanto a uma leitura do mundo que leva em consideração, por exemplo, as questões relativas às classes sociais e ao conflito entre elas resultando, daí, uma visão educacional mergulhada (sem ser aprisionada) em tal conceituação.

\begin{tabular}{l|l|l|l|l|l|l} 
(C) Rev. Educ. Perspec. & Viçosa, $M G$ & v.9 & n.3 & p.576-591 & set./dez. 2018 & eISSN 2178-8359 \\
\hline
\end{tabular}


Também é neste livro que Freire "começa a ver" (segundo suas palavras) a politicidade do ato educativo com maior nitidez, embora a educação ainda não seja explicitada em sua inteireza política, mas apenas em seus "aspectos" políticos. Enfatize-se que a aproximação marxiana-marxista é feita (não-dogmaticamente) através de parâmetros superestruturais relativos ao entendimento das conexões educação-consciência-ideologia-política. Coloque-se, ainda, que as correntes existencialistas e personalistas (definidoras do seu "humanismo idealista" inicial) continuam presentes, agora misturadas com as incorporações do pensamento marxista.

Na sequência da sua obra (após "Pedagogia do oprimido"), nos anos setenta, notaremos certa "limpeza do terreno teórico" na tentativa de desfazer o "amálgama" e encampar outras referências marxistas, a exemplo dos escritos de Antonio Gramsci (1979) e de Freinet $(1978)^{\mathrm{vi}}$. Necessário também assinalar que, apesar da sua importância "em si”, a "Pedagogia do oprimido" faz parte de uma tríade iniciada com "Educação e atualidade brasileira" (1959) e "Educação como prática da liberdade" (1965), isto é, constitui-se sequência de uma obra em constante movimento de reelaboração e de reconstrução. Os três primeiros capítulos do livro, por exemplo, representam o aprofundamento de temáticas tratadas de maneira preliminar em "Educação como prática da liberdade". O último capítulo da "Pedagogia do oprimido" já marca a ultrapassagem e a prospecção teórica fundada nos conflitos sociais e na educação do oprimido nesses conflitos.

Neste sentido, focando o binômio educação-política (eixo condutor do seu pensamento-ação), podemos afirmar que: 1) em "Educação e atualidade brasileira", Freire defende uma prática educativa voltada para o desenvolvimento nacional e para a construção de uma democracia burguesa/liberal; 2) em "Educação como prática da liberdade" advoga uma educação para a liberdade (existencial/personal) em busca da "humanização do homem", via conscientização psicopedagógica; 3) enquanto na "Pedagogia do oprimido" postula um processo educativo para a "revolução da realidade opressora", para a eliminação da "consciência do opressor introjetada no oprimido", via ação político-dialógica.

Os escritos posteriores sediados em Genebra (no Conselho Mundial das Igrejas), com os aportes e colaborações do Instituto de Ação Cultural (IDAC) e os trabalhos nos países de língua portuguesa da África, assim como vários livros dialógicos dos anos 1970/1980, denotam outra etapa, assim como os escritos correspondentes à volta para o Brasil pósAnistia constituem uma terceira fase. Os trabalhos com os movimentos sociais (exemplo: Movimento dos Trabalhadores Rurais Sem Terra - MST), com Prefeituras eleitas do Partido dos Trabalhadores, na Secretaria Municipal de São Paulo, entre outros, outros livros dialógicos dos anos 1980 ("Medo e ousadia - o cotidiano do professor"; "Por uma pedagogia da pergunta"; "Pedagogia: diálogo e conflito", etc.). Entremeados por claras revisões das suas obras/conceitos (como em "Pedagogia da Esperança - um reencontro com a Pedagogia do

\begin{tabular}{l|l|l|l|l|l|l} 
(C) Rev. Educ. Perspec. & Viçosa, $M G$ & v.9 & n.3 & p.576-591 & set./dez. 2018 & eISSN 2178-8359 \\
\hline
\end{tabular}


oprimido", de 1992, e "Política e educação", de 1993) e propostas cada vez mais práticas (como "Pedagogia da Autonomia", 1996), identificam, ao nosso ver, uma fase final dos seus escritos. Isso tudo sem esquecermos os vários livros póstumos publicados sob a coordenação de Ana Maria Freire (2001; 2016 e outros).

Rossi (1981, p. 90-91) caracteriza com clareza a progressão das ideias de Paulo Freire ao afirmar:

\begin{abstract}
Um erro comum na análise do trabalho de Freire é exatamente ignorar-se a clara evolução das suas concepções, que começa por um idealismo moldado por sua vinculação ao pensamento católico moderno, chegando até seu crescimento em direção à abordagem dialética da realidade, que caracteriza seus últimos escritos. Se sua Educação como prática da liberdade é influenciada por concepções de Jaspers e Marcel no nível filosófico, a Pedagogia do oprimido já mostra uma clara aproximação da melhor tradição radical, de Marx e Engels aos modernos revolucionários [...] e de outras linhas de análise crítica contemporânea.
\end{abstract}

De outro ângulo, Peters (2000, p. 105-106) também enfatiza diversas fases do pensamento do educador denominadas liberal, marxista e pós-moderna. Segundo ele:

\begin{abstract}
Claramente, Freire passou por diferentes fases em sua obra refletindo diferentes influências. Simplificando ao máximo, podemos falar em três fases: uma primeira fase liberal dirigida por interesses da Teologia da Libertação; uma mais claramente reconhecível fase marxista e neomarxista, imbuída de um humanismo da fenomenologia ou existencialismo: e, talvez, finalmente, uma fase pós-moderna, onde estava preparado para abrigar as exigências de um pós-modernismo social crítico (e não conservador) e reconhecer como tais exigências condenavam e ajudavam a reescrever aspectos do seu próprio trabalho.
\end{abstract}

Destarte, concordemos ou não com as análises específicas antes colocadas, é importante registrar: embora sejam notórias as evoluções, progressões e/ou fases analisadas por diferentes estudiosos e por ângulos diferentes (SCOCUGLIA, 1999; 2005; ROSSI, 1981; PETERS, 2000; entre outros), a construção da práxis de Paulo Freire possui pilares fundamentais que incluem seu profundo humanismo, sua defesa intransigente da democracia, sua problematização dialógica, sua epistemologia política - entre outros. Certo também que essas fases têm um fio condutor central, qual seja, a inseparabilidade entre a educação e a política que tem como sujeitos principais as camadas populares oprimidas. E não param por aí. Outras obras constituem uma continuidade temática do itinerário indicado (mas não trilhado) por Freire que complementa seu legado. Um dos melhores exemplos pode ser visto nas abordagens de "Ecopedagogia e cidadania planetária" (GUTIERREZ; PRADO, 1999) e de "Pedagogia da Terra" (GADOTTI, 2000). Ou seja, o legado escrito de Freire é extensivo a temáticas não trabalhadas por ele, ou só tocadas brevemente, e que outros pensadores, com os alicerces deixados por ele, trilharam complementando-o.

Em todo esse movimento histórico-epistemológico até aqui esboçado, reiteramos a ideia central de que "Pedagogia do oprimido" é o núcleo articulador das várias fases/etapas da

\begin{tabular}{l|l|l|l|l|l|l} 
(C) Rev. Educ. Perspec. & Viçosa, $M G$ & v.9 & n.3 & p.576-591 & set./dez. 2018 & eISSN 2178-8359 \\
\hline
\end{tabular}


práxis de Paulo Freire. Ou, de outra forma, constitui o vórtice principal da espiral polifônica ${ }^{\text {vii }}$ do movimento permanente de construção/reconstrução do pensamento políticopedagógico de Freire.

\section{O REENCONTRO COM A PEDAGOGIA DO OPRIMIDO E A TRANSIÇÃO PÓS-MODERNA}

Certo é que Paulo Freire revisitou e reescreveu conceitos alocados em "Pedagogia do Oprimido". E o fez de maneira importante em "Pedagogia da Esperança: um reencontro com a Pedagogia do oprimido" reiterando ser este livro a reescrita de partes conceituais significativas da sua obra mais famosa. Assim como também o fez em "Política e educação" (1993). Guevara, Fidel, Mao e outros "revolucionários" (e a própria ênfase focada na "revolução") desapareceram na sequência de "Pedagogia do oprimido", encontrando-se superadas e abandonadas na "Pedagogia da esperança", embora tenha destacado do trabalho político-pedagógico de Amílcar Cabral em "Cartas à Guiné-Bissau” (1980), sob outro prisma, utilizando a via gramsciana não usada anteriormente.

Neste caminho de revisão da "Pedagogia do oprimido" Freire investiu sobre os possíveis esgotamentos da "modernidade" e afirmou a necessidade de nos tornarmos "pós-modernos progressistas”. Vejamos essa sequência conceitual.

O que se faz necessário é que, entre outras coisas, se supere a certeza demasiada nas certezas com que muitos marxistas se afirmavam modernos e, assumindo a humildade em face das classes populares, nos tornemos pós-modernamente menos certos das certezas. Progressistamente pós-modernos (FREIRE, 1992, p. 96-97).

De maneira muito significativa, descartando a ênfase na luta de classes (e, não, a existência de classes sociais) escreve:

O aprendizado, afinal, de que numa nova prática democrática, é possível ir ampliando os espaços para os pactos entre as classes $e$ ir consolidando o diálogo entre diferentes. Vale dizer, ir aprofundando-se as posições radicais e superando-se as sectárias. Isto não significa, porém, de maneira nenhuma que, numa sociedade que assim viva a democracia, uma história sem classes, sem ideologia, se instaure, como proclama certo discurso pragmaticamente pós-moderno até mesmo onde nada ou quase nada disto ocorre. Neste sentido, para mim, a pós-modernidade está na forma diferente, substantivamente democrática, de se lidar com os conflitos, de se trabalhar a ideologia e de se chegar ao socialismo democrático. Há uma pósmodernidade de direita, mas também uma pós-modernidade de esquerda e não como quase sempre se insinua, quando não se insiste, que a pós-modernidade é um tempo demasiado especial, que suprimiu as classes sociais, ideologias, esquerdas e direita, sonhos e utopias. E um dos aspectos fundamentais para a pós-modernidade de esquerda é o tema do poder, o tema da sua reinvenção que ultrapassa o da modernidade, o da sua pura conquista (FREIRE, 1992, p. 198, grifo nosso). 
Mais ainda, revisando a ideia de "revolução" presente na "Pedagogia do oprimido", Freire complementa:

\begin{abstract}
Um dos aprendizados que a pós-modernidade progressista exige de nós é o de que nem sempre a vitória total da revolução evita que, mais adiante, ela se perca. Às vezes, se perde em pleno gozo de seu poder, que ela simplesmente conquistou mas não reinventou, não recriou. Se perde pelo arrogante excesso de certeza das suas certezas, pela consequente falta de humildade, pelo exercício autoritário de seu poder. Se perde por sua modernidade (FREIRE, 1992, p. 198, grifo nosso).
\end{abstract}

Essa visão não se restringe à "Pedagogia da esperança: um reencontro com a Pedagogia do oprimido", mas se estende para um dos seus livros mais importantes deste momento de maturidade de suas ideias: "Política e educação". Freire (1993, p. 15, grifo nosso) escreve:

O que a pós-modernidade progressista nos coloca, diz ele, é a compreensão
realmente dialética da confrontação e dos conflitos e não sua inteligência
mecanicista. [...] Em lugar da decretação de uma nova história sem classes sociais,
sem ideologia, sem luta, sem utopia e sem sonho, o que a cotidianidade mundial
nega contundentemente, o que temos que fazer é repor o ser humano que atua, que
odeia, que cria e recria, que sabe e que ignora, que se afirma e que se nega, que
constrói e destrói, que é tanto o que herda quanto o que adquire, no centro, das
nossas preocupações.

Podemos avançar buscando nos escritos e nas ações propostas na Secretaria Municipal de Educação de São Paulo (fim dos 1980 e começo dos 1990) e perceber essa fase final do pensamento-ação de Freire. Vários conceitos centrais e personagens principais de referência presentes na "Pedagogia do oprimido" da segunda metade dos 1960 não se fazem mais presentes. Freire entendia perfeitamente o novo contexto a exigir conceitos repensados e mesmo o abandono de conceitos antes usados. E não foi só em relação à "Pedagogia do oprimido", nosso foco central neste texto.

Não estão mais presentes, "consciência da realidade nacional" (PINTO, 1960), nem a ênfase em "consciência de classe" (LUCKÁCS, 2012). E, como vimos, sem apagar as "classes sociais", não insiste nem dá destaque principal para "luta de classes", muito menos como "motor único da história". A "consciência de classe", por exemplo, cede lugar para a “consciência das múltiplas subjetividades" presentes na prática educativa.

Por outro prisma, a "história como possibilidade" dos escritos dos anos 1990, eclipsa a teleologia inexorável do marxismo do fim do capitalismo via luta de classes, via "revolução" etc. Agora os dois herdeiros da modernidade (liberalismo e marxismo) encontram-se na berlinda, trincados junto com o edifício da modernidade antes erigido e que serviu de inspiração para Freire em "Pedagogia do oprimido". Não cabem as ditaduras estabelecidas pela via comunista/socialista, a exemplo de Cuba. No "reencontro com a Pedagogia do oprimido", a defesa intransigente da democracia se sobressai ainda mais na afirmação da sua 
"pós-modernidade progressista" de "Pedagogia da esperança" (1992), "Política e educação" (1993) e outros escritos.

Por isso mesmo, reafirmamos um problema central, rico e complicado sobre a obra de Freire como um todo: ela foi construída como sequência de temas que vão se completando de um livro para o outro como um mosaico e como espiral polifônica que retorna ao anterior para poder continuar. Não é nunca linear. É uma obra basicamente de conjunto e não de livros isolados que existem sozinhos e em si mesmos. E isso vale, claro, para "Pedagogia do oprimido". Ademais, não menos importante, sua construção literária é basicamente "oral, dialética" (é tecida a partir das contradições de cada passagem e conceito) e "complexa" no sentido de ser inacabada, incompleta, com muitas arestas e multi/interdisciplinar (MORIN, 2007) e construída-reconstruída como uma "espiral polifônica".

Para este entendimento geral são relevantes as observações dos integrantes do Instituto de Ação Cultural, Rosiska de Oliveira et al. (1974, p. 31-32), seus companheiros no exílio (Europa, África, anos 1970):

\begin{abstract}
[...] todo leitor (de Freire) corre o risco de reter apenas os pontos que lhe interessam diretamente, ou as questões que lhe são compreensíveis devido aos seus marcos de referência. O leitor latino-americano compreende Freire devido a uma experiência de luta política ou envolvendo um movimento social de bases sócio-econômicas. O leitor católico se identifica com a orientação humanista seguida por Freire e compartilha um sentimento de familiaridade com ele e com os filósofos que o influenciaram. O leitor marxista reconhece nos escritos de Freire uma série de correntes contemporâneas com as quais os pensadores marxistas (Gramsci, Lukács, Marcuse) estão acostumados a tratar. O leitor que eventualmente trabalhe com educação encontra traços libertários que caracterizam tendências progressistas presentes no debate pedagógico contemporâneo. Somente aquele que seja todas estas pessoas ao mesmo tempo, ou que tenha, ao longo da sua vida, passado por esses diferentes "estágios" e tenha se submetido a estas diferentes "influências" é capaz de captar o desenvolvimento intelectual de Freire em sua totalidade.
\end{abstract}

Além disso, não podemos esquecer que a escrita de Freire é, geralmente, posterior às suas práticas. Como se tivessem um "atraso", uma "defasagem". Como destacamos no início deste texto, tomando como exemplo a própria "Pedagogia do oprimido", enquanto escrito construído a posteriori das práticas do SESI (Recife, anos 1950), dos movimentos de alfabetização do início dos 1960, e das primeiras práticas chilenas do exílio. Essas práticas geram (depois) a teorização presente na tese de 1959, em "Educação como prática da liberdade", "Pedagogia do oprimido". Essa maneira de teorizar, depois da prática e sempre no sentido de refletir sobre ela para melhorá-la, é fundamental na escrita de Paulo Freire e no próprio entendimento do seu pensamento-ação. Mostram, inclusive, a relação prática-teoria na sua práxis histórico-epistemológica.

Por outro ângulo, as reescritas de "Pedagogia do oprimido" e de outras partes de sua obra também foram lastreadas nas muitas interconexões da sua práxis. Freire fez isso nas várias

\begin{tabular}{l|l|l|l|l|l|l} 
() Rev. Educ. Perspec. & Viçosa, $M G$ & v.9 & n.3 & p.576-591 & set./dez. 2018 & eISSN 2178-8359 \\
\hline
\end{tabular}


etapas dos seus escritos e privilegiou as conexões com outros pensadores, consciente do seu declarado inacabamento. Nesta perspectiva, escrevemos em outro artigo que:

Desde seu início a pedagogia de Paulo Freire se alimenta das suas leituras de base, convergências e conexões com outros pensadores das ciências humanas/sociais e da educação. A partir dos ideais do catolicismo progressista e do nacionalismodesenvolvimentista das décadas de 1950 e 1960 - presentes em suas obras Educação e atualidade brasileira (1959) e Educação como prática da liberdade (1984a) -, do progressismo marxista - presente de maneira crescente em Pedagogia do oprimido (1984b), Ação Cultural para a liberdade e outros escritos (1984c), Educação e mudança (1979) -, passando pelos "escritos africanos", entre outros, até seu declarado "pós-modernismo progressista" - presente em Pedagogia da esperança (1996) -, muitos pensadores influenciaram Freire, em menor ou maior grau. Se Karl Jaspers (1958), Maritain (1966) e Lima Vaz et al. (1962), assim como os ideólogos do ISEB e John Dewey (1971), entre outros, marcaram suas ideias expostas inicialmente e até a metade dos anos 1960, Hegel (1966) e o marxismo "superestrutural" marcam a continuidade desenvolvida em Pedagogia do oprimido (1984b). De lá para cá, esta base foi misturada com as convergências e conexões de ideias que vão de Piaget a Gramsci, chegando às possibilidades de complementos, parcerias, extensões temáticas e reinvenções conceituais. Apesar do legado de Paulo Freire resultar dessas leituras, convergências e conexões, seu pensamento-ação nunca se deixou dominar/enjaular por nenhuma escola ou tendência ideológica. Ao contrário, reconhecendo a necessidade fundante de diálogos teóricos permanentes e tecendo uma obra sequiosa de complementações, construiu um pensamento original e crítico que marcou a pedagogia da segunda metade do século XX e, a nosso ver, demonstra uma prospecção atual vigorosa [...]. (SCOCUGLIA, 2018, p. 200).

Podemos demonstrar tal fato ao identificarmos, a título de exemplo, as principais teses do Relatório Delors/UNESCO (1996) ${ }^{\text {viii }}$, realizado com base na contribuição de pensadores da educação de todo o mundo que prospectam o século XXI, tais como a "aprendizagem e a educação ao longo de toda a vida" e os "pilares da educação" (aprender a aprender, aprender a fazer, aprender a viver juntos e aprender a ser). Ou seja, são evidentes as teses freirianas presentes naquelas eleitas pela UNESCO como representantes fundamentais da passagem do século XX para o século XXI. Com uma importante diferença: para Freire não existem aprendizagens e epistemologias neutras. São, sempre, carregadas da politicidade intrínseca às práticas e reflexões teóricas no campo das ciências da educação. Ademais, a partir das bases e das conexões do amálgama teórico construído por Freire ao longo da formulação do seu pensamento-ação, verificamos que a possibilidade concreta de ser complementado e reinventado é uma das características mais atuais do pensamento de Paulo Freire e de toda carga político-pedagógica do legado freiriano (Scocuglia, 2013, 2015). Mais do que isso: a meu ver tais conexões constituem a própria força motriz da atualidade e da reinvenção de sua práxis. Aliás, a impossibilidade de um só modelo ou de um só autor abarcar a pluralidade e a complexidade das práticas educativas e das reflexões pedagógicas sempre esteve intrínseca às proposições de Freire. Por isso mesmo construiu seu pensamento inspirado em Dewey, Anísio Teixeira, Vieira Pinto, Hegel, Marx, Goldmann, Lukács, Amílcar Cabral, Gramsci, entre outros. Dedicou parte da sua obra aos livros-dialógicos escritos com Frei Betto, Gadotti e Sérgio Guimarães, Ira Shor, Antonio Faúndez, Adriano Nogueira, com os integrantes do Instituto de Ação Cultural - IDAC (Rosiska de Oliveira, Claudius Ceccon, entre outros) etc. Sem olvidar que muitos dos seus escritos foram marcados pela oralidade à espera da interlocução e do diálogo e que suas ideias são estudadas em conexão com Freinet, Habermas, Piaget, Morin, Boaventura Santos e tantos outros (SCOCUGLIA, 2018, p. 202-203).

\begin{tabular}{l|l|l|l|l|l|l} 
(c) Rev. Educ. Perspec. & Viçosa, $M G$ & v.9 & n.3 & p.576-591 & set./dez. 2018 & eISSN 2178-8359 \\
\hline
\end{tabular}


Como construtor (e construído) dos seus diversos tempos históricos e espaços políticos, erigiu o que denominamos "os vários Paulo Freire" tendo o livro "Pedagogia do oprimido" como referência e como núcleo de ligação das demais partes da sua obra escrita. Tal construção foi sustentada pelo seu eixo central humanista, democrático e, acima de tudo, concentrada na inseparabilidade entre a educação e a política. Para este seu movimento próprio, mas nunca isolado, Freire conectou suas práticas e suas teorias com muitos pensadores. Tanto os que serviram de base para seus conceitos e caminhos práticos como outros que completaram seu pensamento - sobre o qual sempre declarou sua incompletude e sua necessidade de diálogos prático-teóricos. Com efeito, ao contrário de demonstrar "defeito ou fraqueza" da sua teorização, suas muitas conexões, reescritas e complementos demonstram a fortaleza de um pensamento que nunca se julgou fechado, completo e unívoco. E que, por isso mesmo, demonstra sua vivacidade, sua atualidade e sua prospectiva nos nossos "tempos líquidos" (BAUMAN, 1999) e de necessários "conhecimentos prudentes" (SANTOS, 2003). Nesta trajetória de escritos entre 1959 e 1996, assim como nos escritos póstumos publicados, sobressaiu "Pedagogia do oprimido" não como um livro acabado e existente em si mesmo, mas, sim, como um dos vórtices da "espiral polifônica" (GADOTTI, 2000) da sua práxis - cuja única parte permanente é o seu movimento.

\section{CONSIDERAÇÕES FINAIS}

Pelo que expusemos neste texto, primeiro em relação ao contexto de escrita da "Pedagogia do oprimido", depois com o "reencontro" de Freire com seu livro mais importante - a rigor, com toda a sua trajetória e produção intelectual -, e, ainda, das interconexões do seu pensamentoação, precisamos considerar, finalmente, os pontos colocados a seguir:

1. Devemos continuar a estudar "Pedagogia do oprimido" não "como uma bíblia", mas como um livro histórico e contextualizado na América Latina em 1967/1968 e cujo conteúdo Freire revisou e modificou com a sua capacidade de autocrítica permanente e sob o foco da sua repetida afirmação: "quanto mais certo estou das minhas certezas, mais eu desconfio delas".

2. Em diversos momentos, Freire se declara incompleto/inacabado e necessitado de complementações que se baseiam nas circunstâncias das práticas dos educadores(as) em cada momento das suas vivências educativas. Gostava de repetir nas suas palestras e encontros com os mais variados interlocutores: "A melhor maneira de me seguir é não me seguindo exatamente".

3. Por isso dialogou com tantos pensadores da sociedade e da educação (cujos exemplos são abundantes), escreveu vários livros dialógicos, criticou posições e práticas mecanicistas,

\begin{tabular}{l|l|l|l|l|l|l} 
(C) Rev. Educ. Perspec. & Viçosa, $M G$ & v.9 & n.3 & p.576-591 & set./dez. 2018 & eISSN 2178-8359 \\
\hline
\end{tabular}


teleológicas, fechadas e intransigentes. Defendeu sempre a "história como possibilidade do novo", do que ainda não existe (inédito viável), não separou a denúncia do anúncio, usou autores os mais diversos (alguns contraditórios) para embasar seus conceitos, apostou na "espiral polifônica" (sem fim) que Gadotti (2000) chamou a atenção.

4. Depois de dezenas de títulos "Doutor Honoris Causa" concedidos por Universidades do mundo, traduzido para dezenas de línguas, reconhecido como parte da Memória do Mundo pela UNESCO, tendo a "Pedagogia do oprimido" como a terceira obra de ciências humanas e sociais mais citada em língua inglesa, considerado um dos 10 educadores mais importantes do século XX, continuamente estudado em países de todos os continentes da Terra, Paulo Freire não precisa de mais homenagens, muito menos ser canonizado por alguma religião pedagógica. Necessita, sim, ser melhor estudado, aprofundado, praticado e "reinventado" como gostava de pensar sobre sua obra.

5. Precisamos discutir sua relevante obra e, na profundidade da sua discussão, descobrir/redescobrir aquilo que continua com o vigor, a força e atualidade de quando foi escrita (1959/1996, além das publicações póstumas), atentos para aquilo que já não mais vigora e, mais ainda, o que pode servir de base para a sua própria reinvenção e para a reinvenção das práticas e das teorias educativas do século XXI.

6. Não acreditamos num suposto "São Paulo Freire" infalível, desprovido de qualquer equívoco e dono de uma obra imaculada, inclusa "Pedagogia do oprimido", que não pode e não deve receber nenhuma crítica. Como se fosse parte de uma bíblia pedagógica!

7. O próprio Freire negou com veemência tudo isso, muitas vezes! Disse enfaticamente que "precisava ser reinventado" pelas circunstâncias de cada prática educativa. Quis reescrever a "Pedagogia do Oprimido" e, dissuadido, escreveu a "Pedagogia da Esperança: um reencontro com a Pedagogia do oprimido" (1992), "Política e educação" (1993), "Pedagogia da Autonomia" (1996). Descartando sectarismos e refletindo sobre os esgotamentos da "modernidade", declarou-se "pós-moderno progressista", ou seja, reconstruiu sua teorização e superou partes da "Pedagogia do oprimido" - como fez várias vezes com outros conceitos a exemplo da "revolução", "luta de classes", "dialogicidade" e da "conscientização".

8. Um exemplo basta para reiterar essa evidência para quem se dedica a ler os escritos de Paulo Freire: o conceito de "conscientização", que reconhece como controverso. Insiste em (re)explicá-lo em muitas faces, algumas contraditórias entre si mesmas: primeiro, usa "consciência da realidade nacional", extraído de Vieira Pinto (1960), seguindo o nacionalismo-desenvolvimentista brasileiro dos 1950; depois enfatiza os "estágios da consciência" do mesmo Vieira Pinto. A seguir, com a adoção do chamado "marxismo cultural" em sua obra, utiliza Lukács (2012) na "consciência de classe". Na maturidade do

\begin{tabular}{l|l|l|l|l|l|l} 
() Rev. Educ. Perspec. & Viçosa, $M G$ & v.9 & n.3 & p.576-591 & set./dez. 2018 & eISSN 2178-8359 \\
\hline
\end{tabular}


seu pensamento-ação, em "Pedagogia da Esperança: um reencontro com a Pedagogia do oprimido", além de outros escritos, aprofunda sua crença nas "múltiplas relações intersubjetivas presentes nas práticas educativas" e chama atenção para a necessidade dos educadores/educadores estarem conscientes de tal ênfase.

9. Importante enfatizar que Freire nunca viu problema em refazer e reconstruir conceitos e paradigmas. Como cientista da prática educativa, complexa por sua natureza múltipla e plural, incentivou a curiosidade, buscando novas possibilidades e novas explicações para as mesmas. Ademais, sempre se declarou incompleto, sequioso de ser complementado e fez isso na prática dialogando com variados pensadores da educação e da sociedade. Fez isso provido da humildade exemplar dos melhores cientistas, que compreendem a necessidade permanente de reconstrução de conceitos e paradigmas como parte intrínseca do desenvolvimento epistemológico, do seguimento do conhecimento e da ciência.

10. Com isso também nos ensinou que a "incerteza é fundamental" nas ciências da educação, assim como em todas as outras ciências. E nos alertou que a caminhada na seara do conhecimento requer a ousadia necessária e a vigilância epistemológica fundamental para evitar o anacronismo das ideias que não conseguem mais compreender e interpretar os mundos macros, mesos e micros que nos impactam na velocidade dos milhões de terabytes por segundos. Sobretudo em tempos de paradigmas frágeis e/ou "líquidos", de mudanças diárias incessantes nas sociedades atuais e de incertezas permanentes. Tempos de "conhecimento prudente para uma vida decente", como advoga Boaventura Santos (2000).

11. Não poderia ser diferente ao continuarmos a estudar sua "Pedagogia do oprimido" como parte nuclear e articuladora da sua obra, mas, sempre "uma parte" (datada, circunstanciada pelo 1968 na América Latina e no mundo ocidental e, portanto, histórica) e, não, a sua totalidade. Parte principal de um discurso e de uma prática que investiu permanentemente no seu próprio movimento de construção e reconstrução, sempre ligado com pensamentos e ideias diferentes e/ou complementares.

12. Por isso mesmo são essenciais as conexões do pensamento de Freire com outros pensadores. Ao nosso ver, repetimos, nessas conexões se encontram algumas das fortalezas atuais do pensamento-ação de Paulo Freire! Ou, talvez, sua principal fortaleza!

13. E por isso, também, continuamos a compreender que aquilo que é essencial, imutável, constante, fixo e sólido na obra escrita e na práxis de Paulo Freire é o seu "movimento histórico-epistemológico"! Tal movimento não cessou com o seu falecimento. Está presente no seu legado (atualizado e prospectivo) que continua a impactar as ciências da educação e as ciências humanas/sociais em pleno século XXI.

\begin{tabular}{l|l|l|l|l|l|l} 
(C) Rev. Educ. Perspec. & Viçosa, $M G$ & v.9 & n.3 & p.576-591 & set./dez. 2018 & eISSN 2178-8359 \\
\hline
\end{tabular}




\section{REFERÊNCIAS}

BAUMAN, Zygmunt. Modernidade líquida. Rio de Janeiro: Zahar, 1999.

FREINET, Célestin. Uma escola para o povo. São Paulo: Martins Fontes, 1978.

FREIRE, Paulo. Educação e atualidade brasileira. São Paulo: Cortez, 1959.

FREIRE, Paulo. Educação como prática da liberdade. Rio de Janeiro: Paz e Terra, 1965.

FREIRE, Paulo. Pedagogia do oprimido. Rio de Janeiro: Paz e Terra, 1968.

FREIRE, Paulo. Ação cultural para a liberdade e outros escritos. Rio de Janeiro: Paz e Terra, 1970.

FREIRE, Paulo. Cartas à Guiné-Bissau. Rio de Janeiro: Paz e Terra, 1980.

FREIRE, Paulo. Pedagogia da esperança: um reencontro com a Pedagogia do oprimido. São Paulo: Cortez, 1992.

FREIRE, Paulo. Política e educação. São Paulo: Cortez, 1993.

FREIRE, Paulo. Pedagogia da autonomia. São Paulo: Cortez, 1996.

FREIRE, Paulo; FREIRE, Ana Maria Araújo (Org.). Pedagogia dos sonhos possíveis. São Paulo: Editora da UNESP, 2001.

FREIRE, Paulo; FREIRE, Ana Maria Araújo (Org.). Pedagogia da indignação: cartas pedagógicas e outros escritos. Rio de Janeiro: Paz e Terra, 2016.

GADOTTI, Moacir. Pedagogia da Terra. São Paulo: Petrópolis, 2000.

GRAMSCI, Antonio. Os intelectuais e a organização da cultura. Rio de Janeiro: Civilização Brasileira, 1979.

GUTIERREZ, Francisco; PRADO, Cruz. Ecopedagogia e cidadania planetária. São Paulo: Cortez, 1999.

LUKÁCS, Georg. História e consciência de classe. São Paulo: Martins Fontes, 2012.

MORIN, Edgar. Introdução ao pensamento complexo. Porto Alegre: Sulina, 2007.

OLIVEIRA, Rosiska Darcy de et al. Freire versus Illich. Instituto de Ação Cultural (IDAC). Document, 8 dezembro de 1974. P. 31-32.

\begin{tabular}{l|l|l|l|l|l|l} 
(C) Rev. Educ. Perspec. & Viçosa, $M G$ & v.9 & n.3 & p.576-591 & set./dez. 2018 & eISSN 2178-8359 \\
\hline
\end{tabular}


PETERS, Michael. Paulo Freire e o pós-modernismo. In: GHIRALDELLI, Paulo (Org.). Estilos em filosofia da educação. São Paulo: DP\&A, 2000. P. 99-108.

PINTO, Álvaro Vieira. Consciência e realidade nacional. Rio de Janeiro: ISEB, 1960.

ROSSI, Wagner. Pedagogia do trabalho: raízes da educação socialista. São Paulo: Moraes, 1981.

SANTOS, Boaventura de Sousa. Conhecimento prudente para uma vida decente. São Paulo: Cortez, 2003.

SCOCUGLIA, Afonso Celso Caldeira. Origens e prospectiva do pensamento políticopedagógico de Paulo Freire. Educação e Pesquisa. São Paulo: EdUSP, v. 2, n. 25, p. 25-37, 1999.

SCOCUGLIA, Afonso Celso Caldeira. Paulo Freire e a conscientização na transição pósmoderna. Revista Educação, Sociedade \& Culturas. Porto: Portugal, n. 23, p. 21-42, 2005.

SCOCUGLIA, Afonso Celso Caldeira. A história das ideias de Paulo Freire e a atual crise de paradigmas. 6. ed. João Pessoa: Editora da UFPB, 2015.

SCOCUGLIA, Afonso Celso Caldeira. As interconexões da pedagogia crítica de Paulo Freire. Revista Filosofia e Educação, v. 10, n. 1, p. 200, 232, jan./abr. 2018.

DELORS, Jacques (Org.). Educação um tesouro a descobrir: Relatório da Comissão Internacional sobre Educação para o Século XXI. Brasília: UNESCO, 1996.

\section{NOTAS}

\footnotetext{
i Texto aprovado e apresentado na mesa redonda "Um reencontro com a Pedagogia do oprimido", no Congresso Internacional "Celebrando Paulo Freire - 50 Anos Depois da Pedagogia do oprimido", realizado pelo Instituto Paulo Freire de Portugal, na Universidade do Porto em 11 de julho de 2018.

ii Sobre a reunião anual da AERA, 2018, ver maiores informações em: <https://convention2.allacademic.com/one/aera/aera18/index.php>. Acesso em: 20 out. 2018.

iii Sobre o programa de homenagem aos 50 anos da "Pedagogia do oprimido" ver em: <https://www.fpce.up.pt/ciie/?q=content/congresso-internacional-50-anos-depois-da-pedagogia-do-oprimido>. Acesso em: 20 out. 2018.

iv Ver, entre nossos outros textos e trabalhos disponíveis on-line, os 30 vídeos do programa Paulo Freire Vivo, da TV UFPB, disponíveis no youtube em: <https://www.youtube.com/results?search_query=paulo+freire+vivo>. Ver outras referências bibliográficas (no final).

${ }^{v}$ Freire gostava de repetir nas suas declarações e entrevistas que não tinha lido Marx para trabalhar com os oprimidos, mas, ao contrário, ao trabalhar com os oprimidos tinha descoberto que Marx o ajudaria a melhor entendê-los.

vi Especialmente quanto aos conceitos de "hegemonia", de "intelectual orgânico" e do "trabalho como princípio educativo".
}

\begin{tabular}{l|l|l|l|l|l|l} 
(C) Rev. Educ. Perspec. & Viçosa, $M G$ & v.9 & n.3 & p.576-591 & set./dez. 2018 & eISSN 2178-8359
\end{tabular}




\section{DOSSIÊ}

vii No prefácio no nosso livro "A história das ideias de Paulo Freire e a atual crise de paradigmas" (SCOCUGLIA, 1999/2015, p. 9-12), Gadotti problematiza a questão da "espiral polifônica" que move o pensamento de Paulo Freire.

viii Este relatório foi publicado no Brasil no formato de livro intitulado "Educação: um tesouro a descobrir" (DELORS, 1996).

\section{Sobre o autor}

1Afonso Celso Scocuglia - Professor Titular da Universidade Federal da Paraíba. Pós-doutorado em Ciências da Educação pela Université de Lyon (França, 2009). Pós-doutorado em História e Filosofia da Educação pela Universidade Estadual de Campinas. E-mail: acscocuglia@gmail.com - ORCID: http://orcid.org/0000-0002-1002-5047 